\title{
Emery-Dreifuss Muscular Dystrophy
}

National Cancer Institute

\section{Source}

National Cancer Institute. Emery-Dreifuss Muscular Dystrophy. NCI Thesaurus. Code C84685.

An X-linked or autosomal dominant inherited muscular dystrophy. It is characterized by slowly progressive muscle weakness, atrial conduction defects, cardiomyopathy, and early contractures of the elbow, ankle and neck. 